\title{
Chemical Stability of Gold Dental Alloys
}

\author{
Debra J.L. Treacy and Randall M. German \\ Materials Engineering Department, Rensselaer Polytechnic Institute, Troy, New York, U.S.A.

\begin{abstract}
The biocompatibility and desirable working characteristics of gold-based alloys are widely recognized in dentistry. Although there has been considerable activity in understanding such characteristics as hardenability, there is perbaps more significance to the chemical stability of a dental alloy since degradation of a dental alloy during service can induce a toxic response and promote gingival tissue irritaion.
\end{abstract}

Because of the recognized role of nobility of a dental alloy in determining chemical stability, various compositional specifications have been issued to help ensure successful service. However, it is recognized that alloys meeting these compositional specifications can prove unacceptable in service $(1,2)$. Conversely there are several alloys in service which appear to perform satisfactorily in spite of an apparently low nobility. These factors serve to illustrate the complex situation which exists concerning acceptance standards for dental alloys; performance standards are regarded as more reliable than compositional standards.

This article describes a study conducted to obtain quantitative tests and data for the tarnish and corrosion behaviour of gold-based dental alloys. The test data necessarily require clinical corroboration to ensure their validity as an indicator of alloy suitability for oral use. However, significant progress has been made in determining the nature of a minimum, yet comprehensive, test battery. In addition, the procedures described in this report show quantitatively a capability of separating the performances of dental alloys in laboratory tests. Data obtained from five commercial alloys are given to illustrate the application of the testing approach.

\section{Background}

The chemical instability of dental alloys has long been recognized as a serious problem. Two distinct occurrences may alter the surface condition of a metal in the mouth; corrosion and tarnish. Corrosion involves the electrochemical dissolution of the metal or the formation of reaction products on the surface. Tarnish is the sufface discolouration duc to the formation of reaction products and is a specific form of corrosion. There have been several previous investigations of both forms of attack and these have been reviewed by German (3).

Because of the more visible nature of tarnish attack, there has been considerable emphasis on this subject in the previous dental alloy studies. Early research in a sulphurized oil bath by Souder and Paffenbarger (4) indicated that 75 weight per cent noble metal in an alloy was necessary to avoid tarnish. Swartz et al. (5) employed 13 different test solutions, using the as-received alloys in an undefined thermal condition, ranked the results in a subjective manner. The general conclusion was that discolouration occurred preferentially in the low nobility alloys when exposed to sulphide solutions.

The study by Tuccillo and Nielsen (6) demonstrated that on a microscopic scale tarnish attack has a galvanic nature. Silver-rich regions were preferentially attacked by the sulphide-containing solution used in their work. Burse et al. (2) examined both the in vitro and in vivo attack of gold-based dental alloys. The in vitro response was measured subjectively after sulphide exposure. This study demonstrated a high variability between patients with respect to in vivo testing, the implication being that there was a need for large patient populations for adequate testing. No significant difference was found in vivo between the two primary test alloys, possibly because of the high variability between patients. Progress towards a quantitative test was provided by Lubovich et al. (7) using sulphide exposure and assessing tarnish by measuring reflected light. A second quantitative measurement method was introduced by German et al. $(8,9,10)$ and was based on the colour changes which accompany tarnishing. Four test solutions were applied to 17 alloys, using clevated tempcratures to accelerate the reactions. The resultsclearly indicated the role of both nobility and microstructure in ranking alloy tarnish resistance. Furthermore, a low correlation coefficient between test solutions was obtained indicating a need for several environmental conditions to be fulfilled in order to fully assess the tendencies of the alloys to tarnish. Based on past research, it is clear that an alloy containing a noble metal content below approximately 40 weight per cent and having a non-uniform microstructure will be susceptible to rapid tarnish. Results supporting these conclusions and, furthermore, showing an effect due to the ratio of the silver and copper contents have recently been reported by Lang et al. (11).

While tarnish and corrosion are not wholly separate phenomena, past experimental reports have tended to treat them differently (12). Various electrochemical techniques have been applied to study the corrosion of gold-based alloys. In the study by Brugirard et al. (13) twelve alloys involving several elements were studied in an artificial saliva solution. The testing was performed at room temperature in an agitated solution using potentiodynamic scans. Brugirard and his co-workers concluded that the height of the current density peaks gave an indication of the relative corrosion tendency of each alloy. Meyer and Nally $(14,15)$ have compared artificial saliva solutions for suitability as dental alloy test media. Based on the response of known alloys in natural saliva, they selected an artificial saliva (termed FKN) developed by Fusayama and his colleagues (16) for potentiodynamic testing. A notable feature of the solution as modified by Meyer and Nally is the presence of a 
small concentration of sulphur. The use of a sulphur-containing artificial saliva solution is supported by the results of the experiments of Popp et al. (17) on gold-based alloys. Other investigators have used potentiodynamic and potentiostatic testing techniques to study the chloride corrosion of gold-based alloys (18-25). Observations on both the forward and reverse scans indicate definite correlations in alloy corrosion rates with noble metal content. However, Sarkar and co-workers (18) warned against using the scans as absolute guides to corrosion resistance due to a lack of discrimination between alloys.

Heat treatments of various alloys (microstructure manipulations) do not affect the corrosion rates measurably. Huget $e t$ al. (25) suggested that alloys of low nobility with rwo phase microstructures exhibit inferior corrosion resistance. The data by Wright and his colleagues (19) show that potentiodynamic scanning corrosion rates correlate with nobility. The further testing by German et al. (20) on 39 alloys showed potentiodynamic scanning in 1 per cent sodium chloride solutions to be capable of quantitatively ranking alloys.

Silver is an important alloying ingredient in dental alloys. Kuhn (26) reviewed several studies and concluded that the anodic dissolution of silver is broadly proportional to the amount of noble metal present. Although nobility is a dominant factor in determining the corrosion resistance, there are other factors which contribute towards the passivation of the more complex commercial dental alloys $(17,20)$. Two studies have indicated that simple sodium chloride solutions are inadequate for characterizing the corrosion behaviour of noble dental alloys $(15,17)$. Small amounts of sulphide ions in the test solution are needed to separate the responses of alloys and to give correlation with clinical observations.

There is evidence for the existence of a correlation between extent of tarnishing, cotrosion and cytotoxicity of gold-based dental alloys $(27,28,29)$. The preliminary evidence indicates that the presence of silver promotes the greatest levels of tarnish and corrosion; however, the corrosion products involving copper cause the greatest cytotoxicity (28). Because of the expense and difficulty of monitoring large patient populations for in vivo testing, the obvious alternative is to develop reliable and rapid laboratory screening techniques for dental alloys. Thus, it was the goal of the present study to design laboratory tests that were both meaningful and quantitative. This goal has been met by developing standardized, quantitative test methods and applying these tests to commercial dental alloys.

\section{Experimental Procedures}

The primary aim of the research reported below was to study the effects of different chemical and physical factors on the chemical stability of gold-based dental alloys. Five commercial alloys having a range of gold contents were selected as shown in Table I. Of the five alloys, only one met the minimum noble metal content required to allow it to be a certified alloy (3). These alloys are based on the gold-silver-copper ternary system. Because of the large two-
Table I

Properties of the Test Alloys

\begin{tabular}{l|r|r|r|r|r}
\hline Property & \multicolumn{5}{|c}{ Values achieved } \\
\hline $\begin{array}{l}\text { Alloy number } \\
\text { Alloy name }\end{array}$ & $\begin{array}{c}1 \\
\text { B-2 }\end{array}$ & $\begin{array}{c}2 \\
\text { Densi- } \\
\text { lay }\end{array}$ & $\begin{array}{c}\text { Neyoro } \\
\text { CB }\end{array}$ & $\begin{array}{c}4 \\
\text { Midi- } \\
\text { gold 50 }\end{array}$ & $\begin{array}{c}\text { Duallor } \\
\text { R }\end{array}$ \\
$\begin{array}{l}\text { Composition, } \\
\text { wt. \% }\end{array}$ & & & & & \\
Au & 74 & 60 & 59 & 50 & 40 \\
Pd & 4 & 4 & 4 & 3 & 6 \\
Ag & 12 & 27 & 23 & 35 & 41 \\
Cu & 10 & $?$ & 14 & 10 & $?$ \\
Vickers hardness & & & & & \\
as-cast & 125 & 155 & 175 & 152 & 120 \\
hardened & 135 & 239 & 275 & 226 & 190 \\
Yield strength, & & & & & \\
MPa & & & & & \\
as-cast & 228 & 296 & 331 & 331 & 241 \\
hardened & 269 & 530 & 751 & 544 & 517 \\
Elongation, \% & & & & & \\
as-cast & 51 & 25 & 44 & 17 & 31 \\
hardened & 42 & 18 & 8 & - & 11 \\
Nobility, atomic \% & 62 & 47 & 45 & 37 & 30 \\
Ag: Cu ratio, & & & & & \\
atomic & 0.71 & 1.77 & 0.98 & 2.06 & 1.76 \\
Manufacturer & Ney & Aderer & Ney & Williams \\
Aderer
\end{tabular}

phase region in this system, the composition of the alloys should affect their microstructures. Furthermore, previous research has shown that microstructure influences the tarnish response (8- 11, 30). Figure 1 shows the ternary phase diagram with the approximate compositional ranges for the five alloys. Alloys 2 and 3 are located in the two-phase region, but adjacent to the single phase boundary. Consequently, it is suspected that tarnishing will vary greatly with heat treatment for these two alloys (30). The compositions of alloys 4 and 5 are situated further into the two-phase region and, consequently, may be less affected by heat treatment. Alloy 1 is higher in gold content and located in the single phase region. Thus, it should not be significantly affected by heat treatment.

The alloys were prepared for study using dental laboratory procedures. Castings were made by the lost wax technique, giving $10 \times 10 \times 2 \mathrm{~mm}$ paddles. The samples intended for tarnish testing were mounted in epoxy and prepared by metallographic procedures to a mirror finish using $50 \mathrm{~nm}$ alumina. They were then ultrasonically cleaned, rinsed with distilled water and stored in a desiccator.

The corrosion samples were also mounted in epoxy, but with a threaded connection through the rear of the mount for electrical contact. The surface was ground to a 600 grit finish in accordance with the standard test method (31). These same samples were heat- 


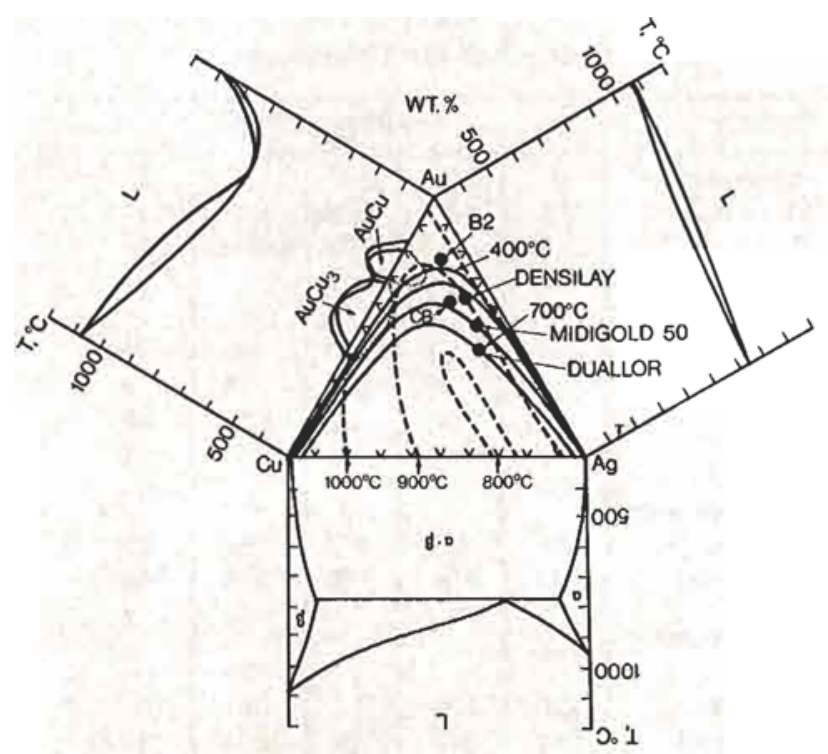

Fig. 1 Approximate locations of the five test alloys on the Au-Ag-Cu ternary phase diagram. The contour lines show the separation between single and two-phase solid regions at various temperatures

treated after testing in the as-cast condition. The surfaces were cleaned by grinding with 240 grit. The heat treatment cycle consisted of annealing at $400^{\circ} \mathrm{C}$ for $30 \mathrm{~min}$ followed by water quenching, which should induce ordering. After heat treating, the alloys were treated in the manner described above.

\section{Tarnish Testing}

The goal of tarnish testing was to establish a reliable, yet minimal test battery. A literature review revealed several prior solutions, methods and techniques for monitoring tarnishing in dental alloys. No technique is generally accepted; however, the rotating wheel apparatus proposed by Tuccillo and Nielsen (6) and the quantitative colour change techniques $(8,9,10)$ are cited frequently. One

\section{Composition of the FKN Artificial Saliva}

\begin{tabular}{l|l}
\hline Component & Amount \\
\hline $\mathrm{NaCl}$ & $0.400 \mathrm{~g}$ \\
$\mathrm{KCl}$ & $0.400 \mathrm{~g}$ \\
$\mathrm{CaCl} \cdot 2 \mathrm{H}_{2} \mathrm{O}$ & $0.795 \mathrm{~g}$ \\
$\mathrm{Na} \mathrm{H}_{2} \mathrm{PO}_{2} \cdot \mathrm{H}_{2} \mathrm{O}$ & $0.690 \mathrm{~g}$ \\
$\mathrm{Na}_{2} \mathrm{~S}_{9} \mathrm{H}_{2} \mathrm{O}$ & $0.005 \mathrm{~g}$ \\
$\mathrm{Urea}$ & $1.000 \mathrm{~g}$ \\
$\mathrm{H}_{2} \mathrm{O}$ & q.s. $1000 \mathrm{ml}$
\end{tabular}

problem has been the lack of control of temperature and solution chemistry using the rotating wheel approach. The rotating wheel apparatus is presently under evaluation, but was rejected for the tests reported here because of evaporation and varying atmospheric conditions. In the present study it was decided to expose samples isothermally in preheated sealed containers to provide close control of the solution conditions. Prior to placing the specimens in a test solution, containers of volume $200 \mathrm{ml}$ were half-filled with fresh solution which had been preheated to the test temperature, and the specimens were placed in individual containers with the polished surface facing upwards. The containers were sealed and maintained in a constant-temperature bath capable of holding temperature to $\pm 0.02{ }^{\circ} \mathrm{C}$. Tarnish testing was conducted at $37^{\circ} \mathrm{C}$. Additionally, elevated temperatures have been used to accelerate the tarnish rate, but the data have indicated that this approach leads to inconsistent results. By consideration of the frec energies of formation for the anticipated tarnish compounds it was estimated that a 58 hour exposure at $60^{\circ} \mathrm{C}$ was equivalent to a 7 day exposure at $37^{\circ} \mathrm{C}$. The resulting tarnish rates and alloy ranking achieved at $60^{\circ} \mathrm{C}$ were not in agreement with those observed at $37^{\circ} \mathrm{C}$. This is attributed to the variation of solubilities and reaction stoichiometries with test temperature. Since this line of investigation proved non-productive, the results will not be presented here.

The selection of a test solution proved to be a difficult task Sulphide solutions have been widely used in previous research. An exhaustive literature search failed to establish the amount of sulphur normally present in the human diet. Consequently, several solutions were tested in the preliminary part of the study, including two artificial saliva solutions, two sulphide solutions, lactic acid and Ringers solution, all of which were found in the literature relating to earlier tarnish testing of gold-based dental alloys (1, 3, 6, 8, 9, 10, 30). Two solutions were selected as being most suitable based on the criteria of tarnish rate, degree of tarnish, statistical significance and repeatability. The two solutions were 0.5 per cent sodium sulphide and the FKN artificial saliva used by Meyer and Nally (14) as listed in Table II. Only the results from these two solutions are reported here; details and results on the other test conditions are given in the thesis by Treacy (32).

The selection of test exposure times proved critical. Priorstudies reported times ranging from ten minutes to eight weeks. With potential applicability to commercial testing in mind, a maximum test duration of one week was used with daily tarnish measurements. It appears to be possible to shorten this further in future studies.

Tarnish measurements were taken using a computerized spectrophotometer. 'The specimens were removed from the solutions, linsed with a water spray and dried with an air jet. After colour measurement, each specimen was returned to its container which had been emptied, rinsed and filled with fresh, preheated solution. Colour measurements were taken on a Macbeth Colorimeter using a standardized light source (CIE source C). Readings were taken with a three-dimensional colour system 
described in detail elsewhere $(8,9,10,33)$. The instrument was calibrated using a fixed white tilc. Prior to testing, each specimen was colour-analyzed and the position on the sample surface marked for future indexing in the instrument. The colour measurements were taken on a $38 \mathrm{~mm}^{2}$ portion of the exposed $100 \mathrm{~mm}^{2}$ area. The incremental readings were compared to the original coordinates to calculate a colour change vector denoted as $\Delta E^{*}$. The magnitude of the colour change is thus related to the magnitude of tarnishing since the CIE scale is fairly uniform. Three samples of each alloy were used in each test. Average colour change vector magnitudes were used in general since the standard deviations were usually small.

\section{Corrosion Testing}

For the corrosion evaluation, a standard electrochemical procedure was adopted. Potentiodynamic curves were used to quantitatively determine corrosion susceptibility. The choice of test solutions for the corrosion testing again required development. Previous studies generally used 1 per cent $\mathrm{NaCl}$ solutions, although artificial saliva and Ringers solutions have also been applied to gold-based alloys (13, 14, 15, 17-25). Based on the correlation obtained with clinical results using the $\mathrm{FKN}$ artificial saliva and the widespread use of 1 per cent $\mathrm{NaCl}$, testing was restricted to these two solutions.

Among the more important parameters in corrosion testing are the solution type, $\mathrm{pH}$, degree of agitation, temperature and oxygen content of the solution. The standard techniquescall for deaetation of the solution prior to testing; however, human saliva always contains some dissolved oxygen. Consequently, tests were performed using both aetated and deaerated solutions. The test instrument is shown schematically in Figure 2 . The potentiostat was an AIS V-2LR-D model with a Scan-4 scanning unit and a built-in log-current converter. The electrochemical cell was temperature controlled to $37^{\circ} \mathrm{C}$ and the $\mathrm{pH}$ monitored. Prior to testing a fresh solution was prepared. The prepared and cleaned specimen was placed in the test cell with an exposed area of $100 \mathrm{~mm}^{2}$. The test solution was preheated to $37^{\circ} \mathrm{C}$ and aerated or deaerated for 15 minutes using air or nitrogen at a flow rate of $150 \mathrm{~cm}^{3} / \mathrm{min}$ prior to sample immersion. An oxygen ion probe showed that these treatments corresponded to dissolved oxygen levels of 6.7 and $0 \mathrm{ppm}$ respectively. The open circuit potential was recorded for 55 minutes before initiating a potentiodynamic scan. Scanning was initiated at $-1.0 \mathrm{~V}$ with respect to a saturated calomel electrode (SCE) at a rate of $1 \mathrm{mV} / \mathrm{s}$. Once the potential reached $1 \mathrm{~V}$, the scanning was reversed to $-1 \mathrm{~V}$. During the entire scan, the current flowing in the circuit was measured and plotted against the applied potential. In many cases the tests for corrosion were repeated three times to ensure repeatable results. The samples were also examined using both optical and scanning electron microscopy, however the data obtained from the use of these two techniques do not form a major contribution to this article.

\section{Results}

\section{Tarnish Testing}

The average colour change was measured for three specimens of each test alloy. The degree of tarnish is related to the colour change from the initial condition. Some variability in tarnish response was noted in the testing, which has subsequently been traced to variation in the sample (and epoxy mount) volume. As mentioned earlier a number of test environments did not give satisfactory tarnish testing. The tarnish colour change produced by a seven day exposure to $37^{\circ} \mathrm{C}$ artificial saliva is shown in Figure 3 . The colour change, or degree of tarnish, achieved a rapid rank ordering in the seven day test period. For alloy 5 the degree of tarnish was extreme, reaching a value of 32 on the colour change scale. After the rapid increase, the rate of attack diminished with time. The five alloys were conveniently separated into three groups with alloys 1 and 2 showing the least attack, and alloys 3 and 4 having an intermediate response. 

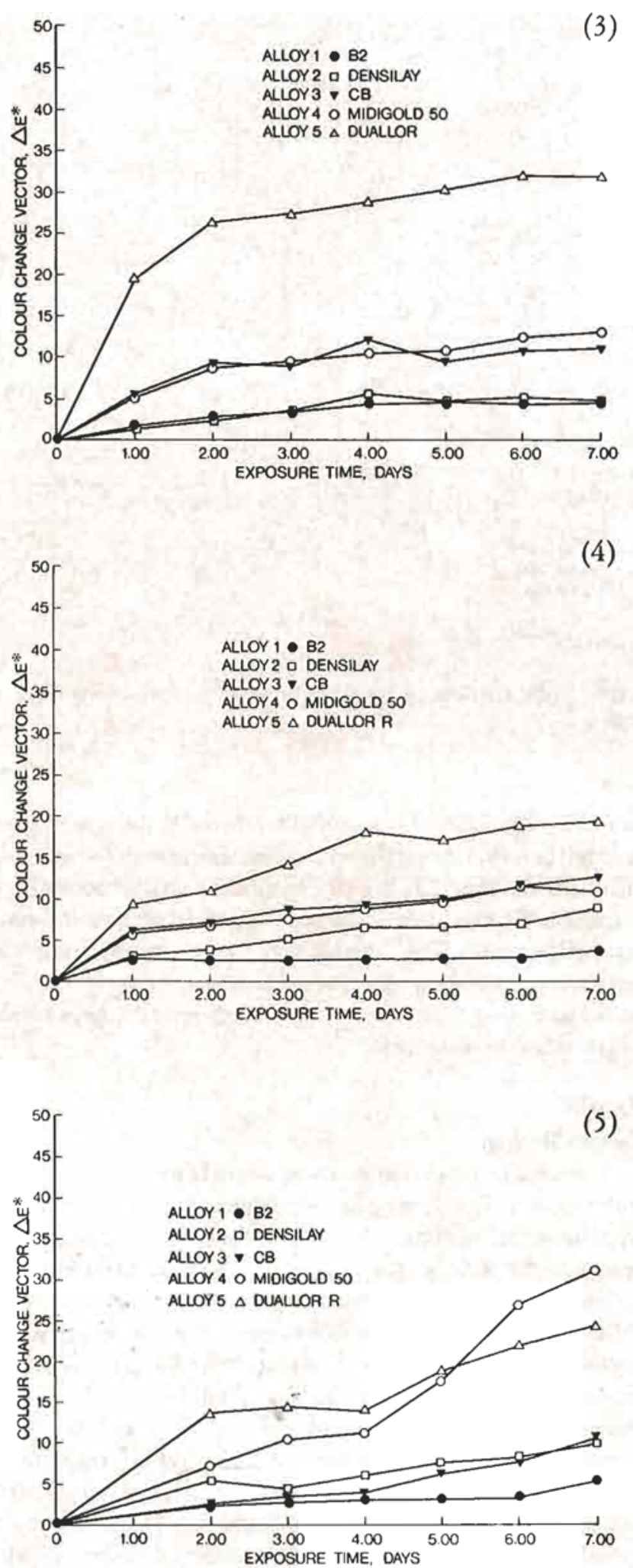

From this test it is apparent that nobility does not solely determine tarnish resistance. Microstructure has a recognized effect $(3,10,30)$ and there is also a possible role played by the ratio of silver and copper contents on tarnish resistance, especially with alloys containing lower gold contents $(10,11)$.

The results of the seven day test in 0.5 per cent sodium sulphide solution at $37^{\circ} \mathrm{C}$ is shown in Figure 4. This solution proved to be less aggressive than the artificial saliva. Again alloy 5 showed the greatest colour change in the test solution. Alloy 1 showed a low degree of colour change, similar in magnitude to that observed in the artificial saliva. Alloy 2 showed less similarity to alloy 1 in this environment, but was still more tarnish resistant than alloys 3,4 and 5. The responses for alloys 3 and 4 were similar to one another, as was also observed in the artificial saliva solution. In both tests, tarnishing of all of the alloys seemed to reach a plateau with respect to time. Such behaviour suggests that the seven day test exposure is more than adequate tocharacterize the tarnish response, and that future testing may be able to determine relative tarnish resistance over shorter durations.

The heat-treated samples were examined for tarnish response in both test solutions at $37^{\circ} \mathrm{C}$. The tarnish responses altered due to the heat treatment, as shown in Figures 5 and 6. Alloy 4 showed a

Fig. 3 A plot of the tarnish colour change $\Delta \mathrm{E}^{*}$ against exposure time for the as-cast gold alloys exposed to artificial saliva at $37^{\circ} \mathrm{C}$

Fig.4 The tarnish colour change $\Delta \mathrm{E}$ * shown as a function of exposure time for the as-cast gold alloys exposed to the $0.5 \% \mathrm{Na}_{2} \mathrm{~S}$ solution at $37^{\circ} \mathrm{C}$

Fig.5 A plot of the colour change $\Delta \mathrm{E}^{*}$ produced by exposure of the alloys to the artificial saliva at $37^{\circ} \mathrm{C}$ after an ordering heat treatment

Fig. 6 The tarnish colour change plotted against time for the heat-treated alloys exposed to $0.5 \% \mathrm{Na}_{2} \mathrm{~S}$ solution at $37^{\circ} \mathrm{C}$

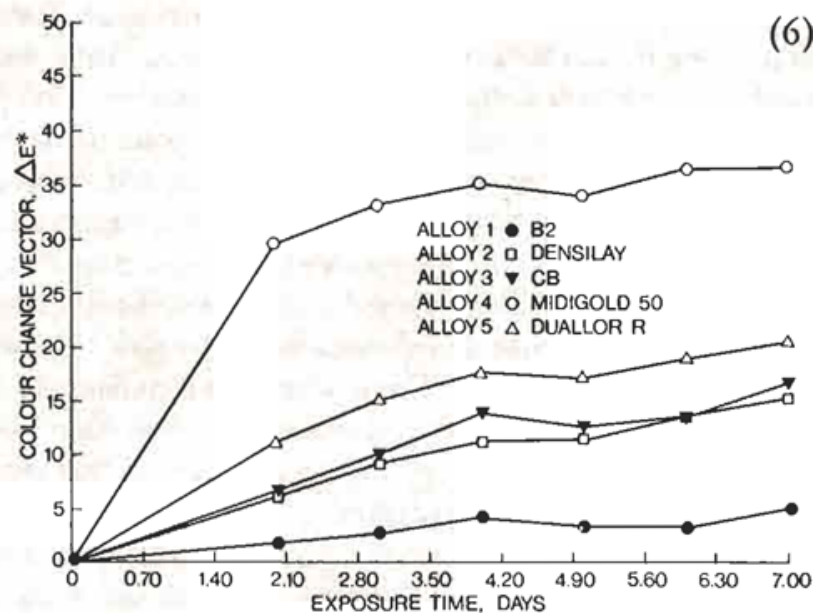


drastic reduction in tarnish resistance following heat treatment. Conversely, heat-treated alloys 1 and 3 showed little change in tarnish behaviour compared to the as-cast condition. Alloys 2 and 5 tarnished more heavily after heat treatment. Alloys with higher silver:copper atomic ratio showed the largest decrease in tarnish resistance with heat treatment. This point is emphasized in Table III, in which the artificial saliva tarnish colour changes are compared for the different alloys. Unlike the as-cast samples, the heat treated specimens did not exhibit plateau behaviour in the seven day exposure. It is evident that the hardening heat treatment is detrimental to tarnish resistance. Of the two solutions, the sulphide proved to be the more aggressive to the heat-treated samples, while, conversely, the artificial saliva was more aggressive to the as-cast samples.

Broadly, examination of the colour change curves produced by tarnish exposures suggests that $\Delta E^{*}$ depends on exposure time as follows:

$$
\Delta E^{*}=k t
$$

where $t$ is the isothermal exposure time, $k$ is constant for a given alloy and solution, and $n$ represents the type of reaction. Table IV shows the results of a statistical fit of the present tarnish colour change data using the above model. The statistical correlations were generally high and significant. A large variation was observed in the $k$ term, while the $n$ value is generally near 0.5 . A diffusion-controlled reaction rate would be associated with such a value implying that tarnishing appears to be diffusion limited by the reaction interface. As the tarnish film grows, it limits further access of the environment to the alloy surface and slows the reaction rate. Based on the good fit of this model and examination of the plots in Figures 3 to 6 , it appears that a test duration of seven days is unnecessary. In most cases, the alloy rank ordering was apparent after the first few tarnish measurements. The artificial saliva solution is preferred because of its relationship to the actual environment in which the alloys are used. After three days of exposure, the highly tarnish-resistant alloys (numbers 1 and 2 in the as-cast condition) showed colour changes of less than five. In contrast, the alloys exhibiting low tarnish resistance showed colour changes of greater than 25 in the same time-period.

\section{Corrosion Testing}

The corrosion tests were selected to provide a quantitative measure of the alloy corrosion resistance. The currents measured in the potentiodynamic scan mode provided a relative indication of the corrosion rank ordering of the alloys. Interpretation of the sample current density curves relies on the knowledge that corrosion resistance is associated with a low current density at any given potential. Also relevant to their interpretation is the fact that a material is more electroactive the more negative the potential at which the current shifts from negative to positive polarity. Overall,
Table III

Total Colour Change $\Delta \mathrm{E}^{\star}$ for Seven Day Exposures to Tarnish Environments

\begin{tabular}{l|c|c|c|c|c}
\hline \multicolumn{1}{c|}{ Property } & \multicolumn{5}{|c}{ Total colour change $\Delta \mathrm{E}^{*}$} \\
\hline Alloy number & 1 & \multicolumn{1}{c}{2} & 3 & 4 & 5 \\
Alloy state and environment & & & & & \\
As-cast & & & & & \\
$\quad 0.5 \% \mathrm{Na}_{2} \mathrm{~S}$ & 3.5 & 8.7 & 12.6 & 10.8 & 19.3 \\
$\quad$ artificial saliva & 4.5 & 4.8 & 11.1 & 13.1 & 32.1 \\
Heat-treated & & & & & \\
$\quad 0.5 \% \mathrm{Na}_{2} \mathrm{~S}$ & 2.5 & 15.4 & 16.7 & 36.5 & 20.4 \\
artificial saliva & 5.3 & 9.9 & 10.7 & 31.1 & 24.3 \\
& & & & &
\end{tabular}

Table IV

Regression Analysis of the Tarnish Data $\Delta E^{*}=k^{n}$

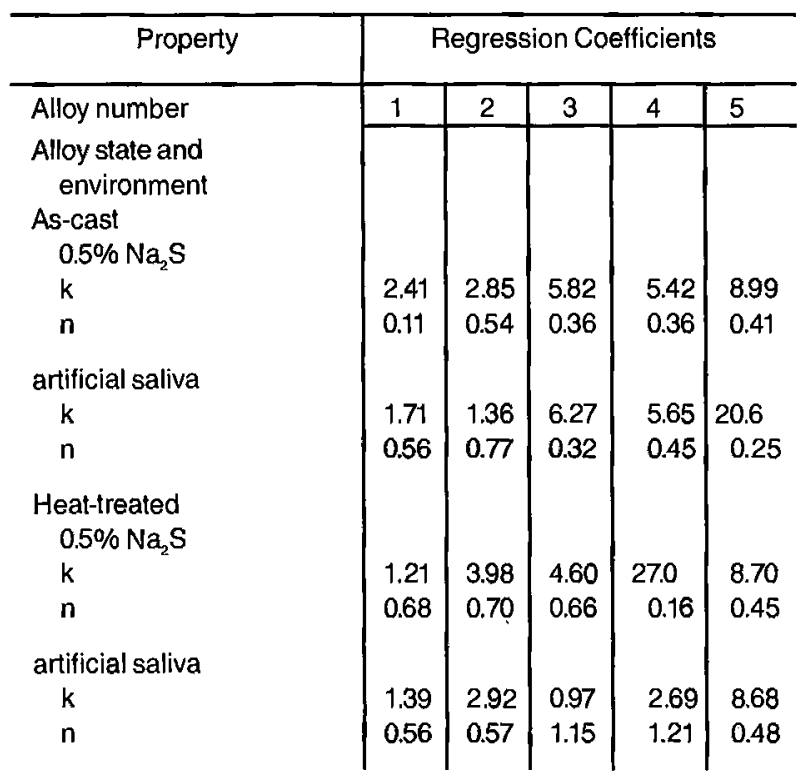

the test battery consisted of five alloys, two solutions and two aeration conditions, with both forward and reverse scans. In addition, there were various tests carried out on heat-treated samples. An overview of the results of these tests is given with emphasis on the data obtained from the 1 per cent sodium chloride solution.

The forward and reverse potentiodynamic scans for the five alloys in aerated 1 per cent sodium chloride at $37^{\circ} \mathrm{C}$ are shown in Figures 7 and 8 in which logarithmic current density is plotted against linear applied voltage (with respect to the saturated calomel electrode). The forward scan corresponds to the initial polarization from $-1 \mathrm{~V}$ up to $1 \mathrm{~V}$. During such scans the reaction shifts between 


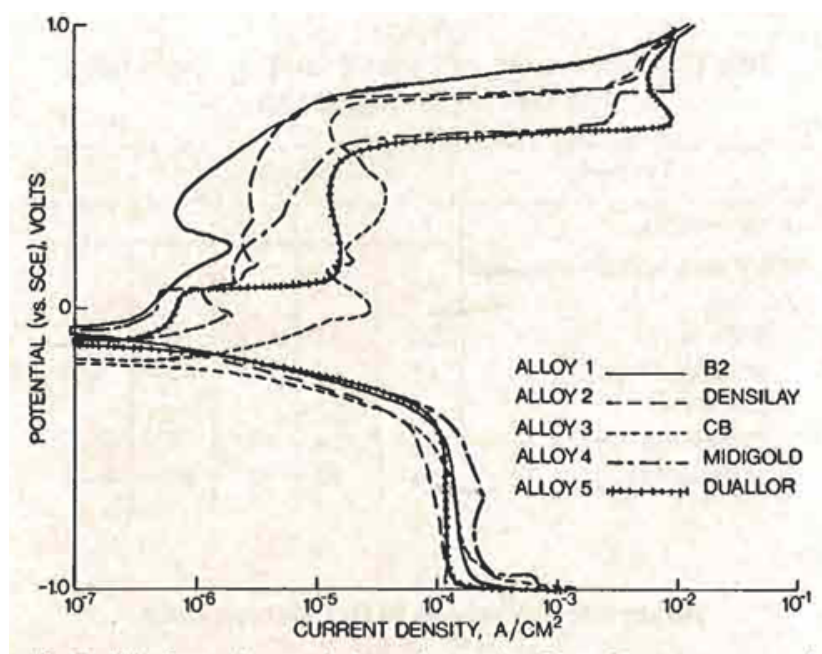

Fig.7 The forward potentiodynamicscans $(-1 \mathrm{~V}$ to $1 \mathrm{~V}$ versus a saturated calomel electrode at a scan rate of $1 \mathrm{mV} / \mathrm{s}$ ) in aerated $1 \% \mathrm{NaCl}$ for the as-cast alloys

Fig. 8 The reverse potentiodynamic scans in aerated $1 \% \mathrm{NaCl}$ solutions for the as-cast alloys

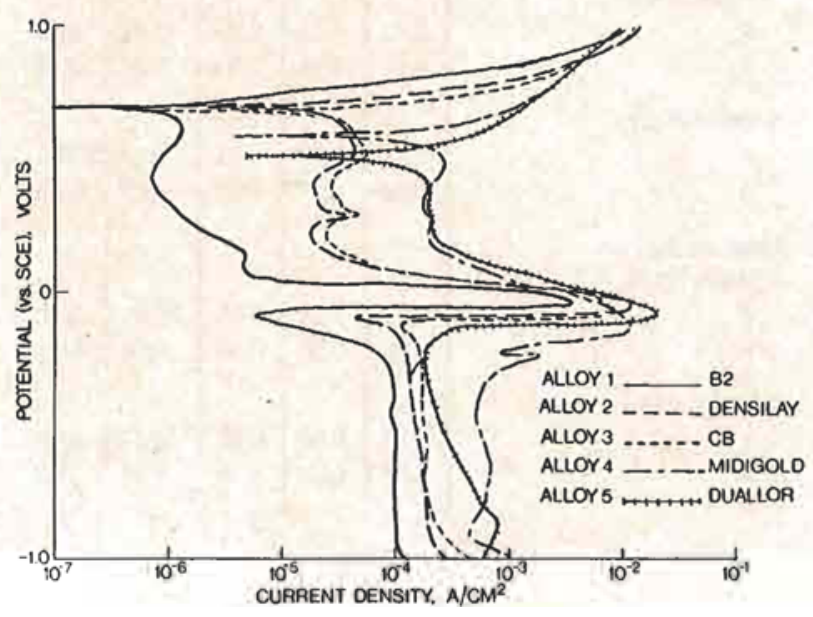

reduction and oxidation control; however, on a logarithmic scale only the current magnitude can be shown, not the sign. Hence the point at which the two reactions are in balance appears as the voltage at which the lowest current density is achieved, termed the corrosion potential (the potential at $10^{-6} \mathrm{~A} / \mathrm{cm}^{2}$ ). The corrosion potential and the current densities at potentials above it provide the best indicators of corrosion behaviour. Comparing the corrosion potentials it can be seen that those in the deaerated sodium chloride were only slightly more negative than those observed in artificial saliva. The ordering of alloys from most to least corrosion resistant,

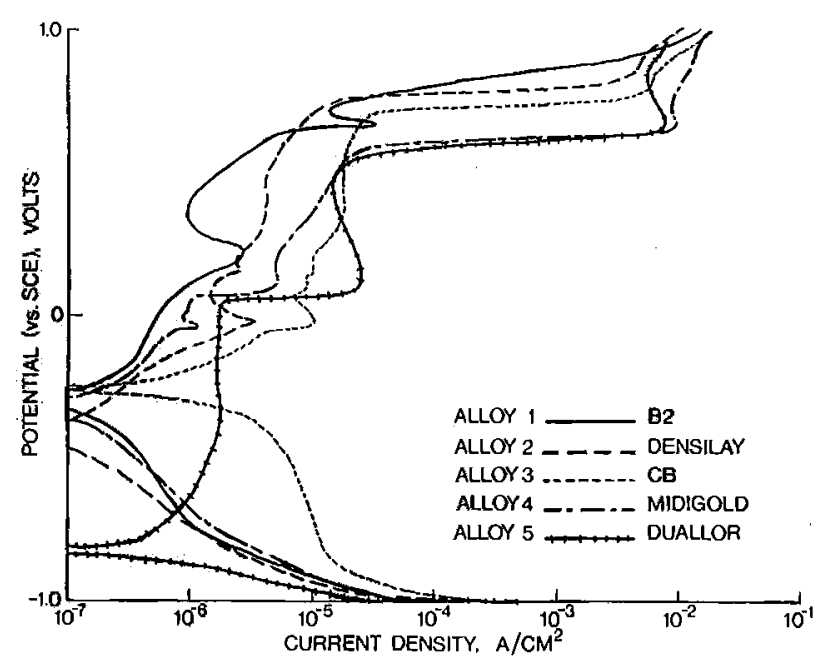

Fig. 9 Forward potentiodynamic scans in deaerated $1 \% \mathrm{NaCl}$ solutions for the as-cast alloys

generally followed the ranking 1, 2, 4, 5 and 3 in deaerated sodium chloride. This ranking was preserved in the artificial saliva solution. In the reverse scans shown in Figure 8, the large peak at $0 \mathrm{~V}$ indicates a high level of silver corrosion (16). The equivalent scans in deaerated 1 per cent sodium chloride at $37^{\circ} \mathrm{C}$ are given in Figures 9 and 10 . The major difference between the aerated and deaerated forward scans was a shift of the corrosion potentials. A slight reduction in corrosion currents in apparent, but this is not significant enough to alter the alloy rank ordering in corrosion resistance. On the reverse scans, shown in Figure 10, a slightly reduced corrosion rate is observed. The presence of dissolved oxygen makes all of the alloys more noble.

Figure 11 shows the behaviour of the five alloys in the forward scan using the aerated artificial saliva. In contrast to the other figures, there is less discrimination between alloys in this test. A further difficulty is the complex chemistry occurring in this solution, in which the presence of oxygen masks the electrochemical reactions. The measured current density represents the difference between the oxidation and reduction rates, thus oxygen in the test solution promotes the corrosion potential. In general, the aerated solutions yielded less information than the anaerobic scans. Hence, in a complex solution like the aerated artificial saliva, the oxidation reactions interfere with the determination of the actual corrosion rate. Although this is a more realistic solution, the inability to measure the electrochemical behaviour accurately is clearly detrimental to its use alone.

Potentiodynamic tests were conducted on heat-treated alloys. In general the shifts in corrosion behaviour were favourable. In both solutions, the heat-treated samplesshowed lower corrosion current 


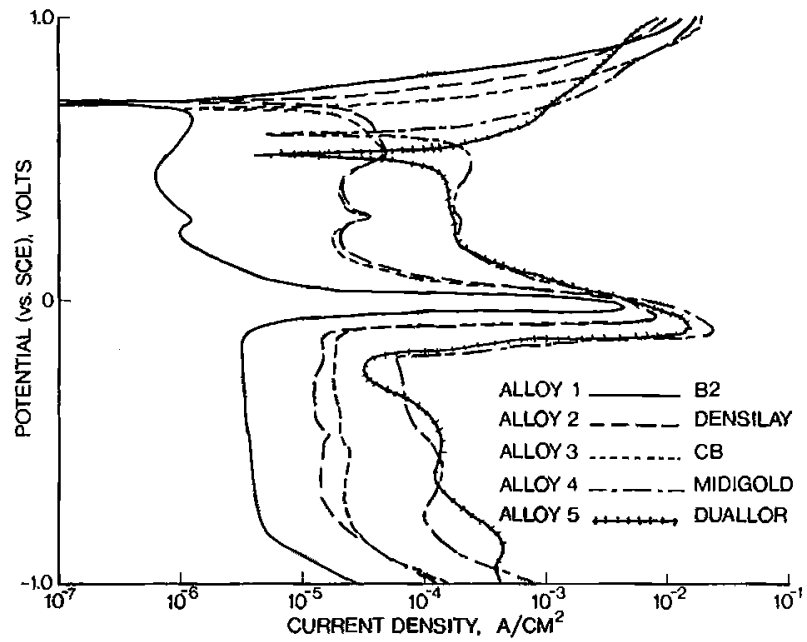

Fig. 10 Reverse potentiodynamic scans in deaemted $1 \% \mathrm{NaCl}$ solutions for the as-cast alloys

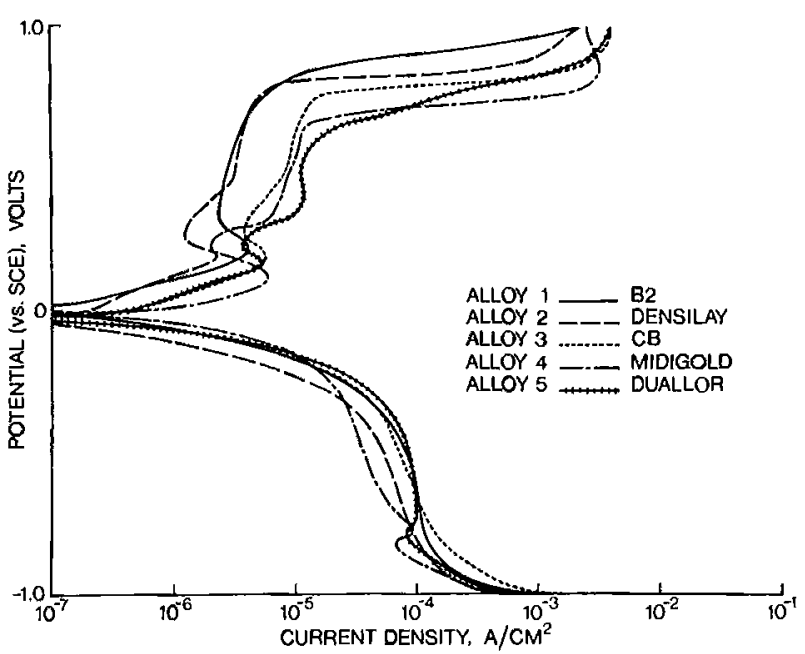

Fig. 11 Forward potentiodynamic scans for the as-cast alloys in aerated arcificial saliva at $37^{\circ} \mathrm{C}$

Table $V$

Current Density Peaks at $200 \mathrm{mV}$ (Forward Scan), in $\mu \mathrm{A} / \mathrm{cm}^{2}$ and $0 \mathrm{mV}$ (Reverse Scan), in $\mathrm{mA} / \mathrm{cm}^{2}$ the heat treatment, appears to slightly increase corrosion resistance. However, the actual change in corrosion behaviour between the ascast and heat-treated samples was relatively minor. This is very different from the tarnish tests where heat treatment proved detrimental to the alloys. The potentiodynamic scans point to alloy nobility being the primary factor determining overall corrosion resistance. Alloy 1 which has the highest gold content always exhibited the best corrosion resistance. In contrast, alloy 5 with the lowest gold content proved consistently to be the least corrosion resistant. Alloys 2 and 3 were similar and more corrosion resistant than alloy 4 .

The value of current density at various potentials has been proposed as a quantitative measure of corrosion (19). Table V shows the current densities at $200 \mathrm{mV}$ on the forward scan and $0 \mathrm{mV}$ on the reverse scan in six test conditions. Nobility is clearly a dominant factor. However, this method of comparison of corrosion results does not always best reflect the observed potentiodynamic scan behaviour. The results of this study suggest that use of the total scan and comparison at several voltages is a better overall-basis for assigning relative corrosion resistance to alloys.

\section{Discussion and Conclusions}

This study has achieved an insight into the development of a quantitative test battery for measuring dental alloy corrosion and tarnish resistance. The tarnish testing was performed with simple immersion exposures to sulphide and artificial saliva solutions. Both tests produced significant amounts of tarnish during a seven-day

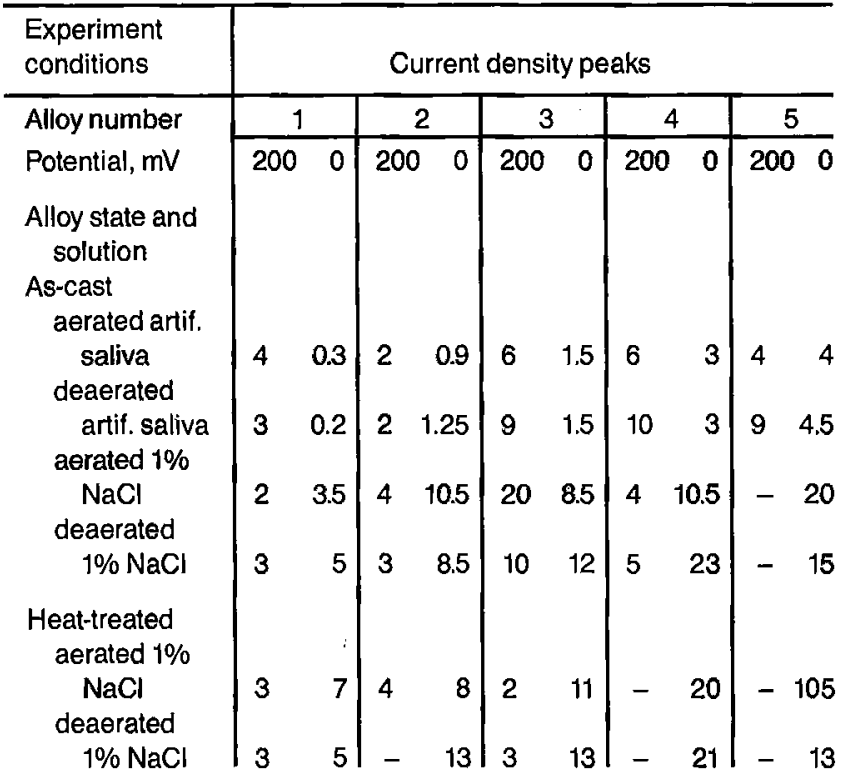

exposure, as measured using a spectrophotometer. Colour change provided an accurate, quantitative measure of tarnishing. The resulting numerical ranking was valuable in comparing the five test alloys. A seven day test at $37^{\circ} \mathrm{C}$ is more than adequate for determining the characteristic tarnish response on an alloy. 
Although accelerated tests are desirable for commercial reasons the accelerated testing performed at $60^{\circ} \mathrm{C}$ did not produce the same tarnish response. Both the degree of tarnishing and the relative ranking of alloys were altered by the high temperature accelerated tests.

It has been observed that tarnish response is not solely dependent upon nobility. Other factors such as the environment, ratio of clements in the alloy and heat treatment can alter the alloy's tarnish resistance. Conspquently, an examination of the role of microstructure would be important in creating a better understanding of tarnish behaviour. Data from the as-cast, medium-nobility alloys suggest that a high silver : copper ratio is favourable. Hardening heat treatments are expected to change the microstructure of these alloys and to allow ordering. The five alloys were subjected to standard heat treatments and as a result often exhibited inferior tarnish resistance. It may be possible to favourably manipulate the tamish resistance of gold dental alloys by the use of selected heat treatments.

Analysis of the time dependence of the extent of tarnishing indicates that an interfacial diffusion controlled mechanism operates in the process. Consequently, accurate rank ordering of alloys should be possible using fairly short test times. The tarnish resistance of the five commercial alloys indicates that both chemical and microstructural factors are important. It should be stressed that these are commercial alloys with some measure of success in use in humans. Thus, the relative tarnish responses of these in the present artificial saliva and sulphide solutions provide a baseline against which other alloys can be evaluated.

Two solutions have been used for corrosion testing in the potentiodynamic mode; 1 per cent sodium chloride and an artificial saliva. The relative corrosion of the five alloys was similar in both solutions, although the salt solution was slightly more aggressive. Testing was performed under both aerated and deaerated conditions to determine the role of dissolved oxygen. The presence of dissolved oxygen in solution improved the apparent corrosion resistance. Under deacrated conditions the potentiodynamic curves reflect a rariking of the alloys according to their performance. Alloy chemistry appears to be the major factor determining alloy corrosion resistance. The corrosion tests were performed on both as-cast and heat-treated specimens. Unlike the tarnish behaviour, corrosion of the alloys was little affected by the structural change associated with heat treatment. The use of the characteristic current density peak magnitudes corresponding to silver and copper corrosion did not always support the rankings obtained by comparison of the overall curves. Consequently, it is suggested that future comparisons be based on the entire corrosion curves and not only values of currents at specific voltages.

This research has developed testing procedures and solutions that form the groundwork for quantitative testing of gold-based dental alloys. Several factors need further study such as the relation between tarnish resistance and the atomic ratio of silver to copper present in the gold alloy. The test battery will require corroboration by clinical data to establish a link between the laboratory results and market acceptability. It is hoped that such data will confirm that the test methods developed and reported here will be capable of predicting the tarnish and corrosion behaviours of gold dental alloys. In the interim, the existing data on commercial gold-based alloys provide a baseline for comparison. It is evident that corrosion resistance is best assured by high nobility, that is high gold content; however, tarnish resistance is influenced not only in the same way by nobility, but also by composition and microstructure.

\section{Acknowledgements}

This study was cartied out in the Materials Research Center at Rensselact Polytechnic Institute supported by the International Gold Corporation. The computer analyses were performed by Tracey Margraf, whose assistance is gratefully acknowledged. Our thanks go to the alloy manufacturers for the loan of the test materials; J.M. Ney Co., J. Aderer Inc., and Williams Gold and Refining Co.

\section{References}

1 J.J. Bates and A.G. Knapton, Intermat. Met. Rev., 1977, 22, 39-60

2 A.B. Burse, M.L. Swartz, R.W. Phillips and R.W. Dykema, J. Biomed. Mater Res, $1972,6,267.277$

3 R.M. German, Intemat. Met. Reu, 1982, 27, 260-288

4 W. Souder and G.C. Paffenbarger, Physical Properties of Dental Materials, Circular C433, National Bureau of Standards, Washington, D.C., 1942

5 M.L. Swartz, R.W. Phillips and M.D. El Tannir,J. Dent. Res., [958,37, 837-847

6 J.J. Tuccillo and J.P. Nielsen, J. Proith. Dent., 1971, 25,629-637

7 R.P. Lubovich, R.E. Kovarik and K.L. Kinser, J Prosth. Dent, 1979, 42, 534-538

8 R.M. German, M.M. Guzowski and D.C. Wright, J. Met., 1980, 32, (1), 20-27

9 R.M. German, D.C. Wright and R.F. Gallant J. Prosth. Dent., 1982, 47, 399-406

10 R.M. German, Metallography, 1981, $[4,253-266$

11 B.R. Lang, S.H. Bernier, Z. Giday and K. Asgar, J. Prosth. Dent., 1982, 48, 245-252

12 L.W. Laub and J.W. Stanford, Gold Butl., 1981, 14, (1), 13-18

13 J. Brugirard, R. Bargain, J.C. Dupuy, H. Mazille and G. Monnier, J. Dent. Res,, $1973,52,828-836$

14 J.M. Meyer and J.N. Nally, J: Dent. Res., 1975, 54,678-683

15 J.M. Mever, Com. Sci, 1977, 17, 971-982

16 T. Fusayama, T. Katayori and S. Nomoto, J. Dent. Res, 1963, 42, 1183-1197

17 W. Popp, H. Kaiser, H. Kaesche, W. Bramer and F. Sperner, in 'Proc. 8th International Congress on Metallic Corrosion', National Association of Cortosion Engineers, Houston, 1981, pp. 76-81

18 N.K. Sarkar, R.A. Fuys, Jr. and J.W. Stanford, J. Dent. Res., 1979, 58, 568-575

19 D.C. Wright, R.M. German and R.F. Gallant, J. Dent. Res, 1981, 60, 809-814

20 R.M. German, D.C. Wright and R.F. Gallant, 'Precious Metals', edited by R.O. McGachie and A.G. Bradley, Pergamon Press, Toronto, 1981, pp. 253-257

21 N.K. Sarkar, R.A. Fuys, Jr and J.W. Stanford, J. Prosth. Dent., I978, 40, 50-55

22 N.K. Sarkar, R.A. Fuys, Jr, and J.W. Stanford, J. Dent. Res, 1979, 58, 1572-1577

23 S.R. Wright, E.H. Cocks and L. Gettleman, J. Dent. Res., 1980, 59, 708-714

24 L. Gettleman, FH. Cocks, L.A. Darmiento, P.A. Levine, S. Wright and D. Nathanson, J. Demt. Res., 1980, 59, 689-707

¿s E.F. Huper, F.A. Modawar, S.G. Vermilyea and L B. de Simon, Mil. Med., 1980, $145,701-703$

26 A.T. Kuhn, Brit, Com J., 1982, 17, 51-58

27 H. Nagem-Filho, D.E. Vicira, P.A. DeAraujo and J. Chiodi-Netto, J. Prosth. Dent., 1975, 33, 542-546

28 D. Wright, R. Gallant and L. Spangberg 'Precious Metals 1981', edited by E.D. Zysk, Pergamon Press, Toronto, 1982, pp. 433-441

29 C.R. Culliton, M.A. Meenaghan, S.E. Sorensen, G.W. Greene and J.D. Eick,J. Biomed. Mater: Res., 1981, 15, 565-575

30 H. Hero and R.B. Jorgensen, J. Dent. Res, 1983, 62, 371-376

31 American Society for Testing Materials Standards, Specification G5-78, Part 10 1978, pp. $816-826$

32 D.J.L. Treacy, 'Quantitative Characterization of the Chemical Stability of Gold Dental Alloys'. M.S. Thesis, Renssclaer Polytechnic Institute, Troy, New York, 1983

33 FW. Billmeyer, Jr. and M. Saltzman, 'Principles of Color Technology',John Wiley and Sons, New York, 1966 